\title{
Purification of 2-methoxyethyl 1-methylethyl 2,6-dimethyl-4-(3-nitrophenyl)pyridine-3,5-dicarboxylate by preparative high-performance liquid chromatography
}

\author{
I. Medina
}

Departamento de Ingeniería Química, Universidad de Oviedo, 33071 Oviedo, Spain

\begin{abstract}
The 2-methoxyethyl 1-methylethyl 2,6-dimethyl-4-(3-nitrophenyl)pyridine-3,5-dicarboxylate was obtained in a 99.8\% pure form from raw material by preparative-scale high performance liquid chromatography. This compound is an impurity in the industrial process of nimodipine. The chromatographic conditions were optimized to achieve any efficient purification in the shortest time. A reversed-phase preparative-scale HPLC column was used. This work demonstrates how gram quantities of pure material can be conveniently obtained using preparative HPLC, even when the components in a mixture are difficult to resolve.
\end{abstract}

Key words. Calcium antagonist - nimodipine - column liquid chromatography - preparative scale separation.

\section{Introduction}

The calcium antagonists are a heterogeneous group of cardiovascular drugs used to block the entry of calcium ions into nerve cells, producing a reduction in peripherical vascular resistance. This class of compounds (dihydropyridines) are 4-aryl-1,4-dihydropyridine 3,5-dicarboxylates. The ester functions in the 3,5-positions may be varied widely without a significant reduction in potency. They proved, however, to be important in respect to vascular selectivity and duration of action, both of which are critical parameters for the selection of an antihypertensive agent. The calcium antagonist nimodipine is chemically isopropyl-2-methoxyethyl 2,6dimethyl-4-(3-nitrophenyl)-1,4-dihydropyridine-3,5-dicarboxylate. Nimodipine is used for the prevention or treatment of delayed ischaemic dysfunction following subarachnoid haemorrhage, and is currently widely studied in impaired brain function in old age and in senile dementia [1-5]. The chemical synthesis of nimodipine leads some pyridine derivatives as well. The most important impurities are: a) 2methoxyethyl 1-methylethyl 2,6-dimethyl-4-(3-nitrophenyl)pyridine-3,5-dicarboxylate, b) bis(1-methylethyl) 2,6-dimethyl-4-(3-nitrophenyl)-1,4-dihydropyridine-3,5dicarboxylate, and c) bis(2-methoxyethyl) 2,6-dimethyl-4-(3nitrophenyl)-1,4-dihydropyridine-3,5-dicarboxylate.

The quality requirements for pharmaceutical compounds continue to become even more stringent. As a result, the choice of purification processes and the optimization of purification conditions have became increasingly important. Purification is a key process for the commercialization of chemical compounds. This is especially the case of pharmaceutical compounds which require high quality.
The impurity (a) must be controlled in the industrial process of nimodipine. It is necessary to have a standard of this compound to check the production of nimodipine. Chemical structures of nimodipine and its impurities are shown in figure 1.

The present paper describes the optimization of chromatography methods from analytical to preparative scale using silica $\mathrm{C}_{18}$ as stationary phase to isolate gram quantities of analytically pure 2-methoxyethyl 1-methylethyl 2,6dimethyl-4-(3-nitrophenyl)pyridine-3,5-dicarboxylate. There is not any reference in the literature describing a chromatographic method to purify this compound.

Analytical high-performance liquid chromatography (HPLC) is a widely applied technique and its obvious extension, preparative HPLC, is now well developed and it may be utilized succesfully in the quantitative separation of complex mixtures [6-9].

\section{Experimental}

\section{Apparatus}

The instrumentation used for analytical chromatography was from Waters (Milford, MA, USA) consisting of a Waters 600E Gradient Module, a Waters 484 tunnable absorbance detector and a Waters 745B recorder. The Waters 484 detector was equipped with a $10 \mathrm{~mm}$ flow cell path length.

For preparative chromatography, the high performance liquid chromatographic apparatus consisted of a Waters Delta Prep 4000 equipped with a Rheodyne sample injection

Received January 26, 1999; revised April 29, 1999; accepted May 10, 1999 


\section{Original articles}<smiles>COCCOC(=O)C1=C(C)NC(C)=C(C(=O)OC(C)C)C1c1cccc([N+](=O)[O-])c1</smiles><smiles>COCCOC(=O)c1c(C)nc(C)c(C(=O)OC(C)C)c1-c1cccc([N+](=O)[O-])c1</smiles><smiles>CC1=C(C(=O)OC(C)C)C(c2cccc([N+](=O)[O-])c2)C(C(=O)OC(C)C)=C(C)N1</smiles><smiles>COCCOC(=O)C1=C(C)NC(C)=C(C(=O)OCCOC)C1c1cccc([N+](=O)[O-])c1</smiles>

Fig. 1. Chemical structures of nimodipine and its impurities: a) 2methoxyethyl 1-methylethyl 2,6-dimethyl-4-(3-nitrophenyl)pyridine3,5-dicarboxylate, b) bis(1-methylethyl) 2,6-dimethyl-4-(3-nitrophenyl)-1,4-dihydropyridine-3,5-dicarboxylate, and c) bis(2-methoxyethyl) 2,6-dimethyl-4-(3-nitrophenyl)-1,4-dihydropyridine-3,5-dicarboxylate.

valve (Model 7010) (Rheodyne, Cotati, CA, USA), an automatic sample loader (Waters 170), a Waters 484 tunnable absorbance detector, a Waters $745 \mathrm{~B}$ recorder and a Waters fraction collector to recover the isolated compounds. The $3 \mathrm{~mm}$ path length of the 484 detector's preparative flow cell is ideal when high concentrations of UV absorbing material are present.

\section{Materials}

2-methoxyethyl 1-methylethyl 2,6-dimethyl-4-(3-nitrophenyl)pyridine-3,5-dicarboxylate was supplied by Astur
Pharma (Asturias, Spain) and it was obtained by chemical synthesis. Some grams were synthesized in the laboratory of the Research and Development Department according to the Michael addition procedure using 1,4-dihydropyridine with appropiate functionality as precursor. Solvents for chromatographic separations (methanol and water) were LiChrosolv grade (Merck, Darmstadt, Germany). Mobile phases were filtered through a $0.2 \mu \mathrm{m}$ filter (Millipore, Bedford, MA, USA) and degassed prior to use.

\section{Columns}

For analytical separations a Nucleosil $\mathrm{C}_{18} \quad 100 \AA(4.6 \times$ $250 \mathrm{~mm}, 10 \mu \mathrm{m})$ column was used. Preparative separations were conducted on a Nucleosil $\mathrm{C}_{18} 100 \AA(22 \times 250 \mathrm{~mm}$, $10 \mu \mathrm{m})$ column. Prior to use and at the end of a day of multiple runs, the columns were washed with acetonitrile.

\section{Results and discussion}

The 2-methoxyethyl 1-methylethyl 2,6-dimethyl-4-(3-nitrophenyl) pyridine-3,5-dicarboxylate was analytically chromatographed in order to characterize and separate the impurities and to develop conditions for use in a wider diameter column of the same packing material. Analytical separation was achieved using a reversed phase column Nucleosil $\mathrm{C}_{18} 100 \AA$ A. $20 \mu \mathrm{g}$ sample of crude pyridine $(20 \mu \mathrm{L}$ of a 1 $\mathrm{mg} \mathrm{mL}^{-1}$ solution in the mobile phase) was injected into the column and it was chromatographed at a flow rate of $1 \mathrm{~mL}$ $\mathrm{min}^{-1}$. The analysis were carried out with methanol-water $(75: 25)$ as mobile phase at ambient temperature. Good separation between pyridine and the impurities was obtained. The column effluent was monitored at $254 \mathrm{~nm}$. Figure 2 shows the analytical chromatogram. All the peaks identified have been labeled in the figures. The analysis showed a purity of $90.2 \%$. Standard curves were run showing that absorbance was linear for the concentration ranges encountered for the compound used in the experiments. The chromatographic conditions were used to determine the operating conditions of the preparative system.

Whereas analytical chromatography emphasizes the resolution and identification of each fraction that elutes from the column, preparative chromatography emphasizes the purity and yield of the desired final product. The quantity of sample that can be processed in a given time is referred to as throughput, an important factor in scaling up. If large amounts of purified material are needed the column should be overloaded. Even though peaks are overlapping, a heartcut will produce a highly purified component with a greater throughput per unit of time than is possible by separation at the loading limit [10-12].

There are two ways in which a column may be technically overloaded. First, the volume of the injected sample may be so large that eluted peaks are significantly wider than those from analytical samples. Second, the concentration or quantity of solute injected may be so high that, even with a very small injection volume, the resulting peak is 


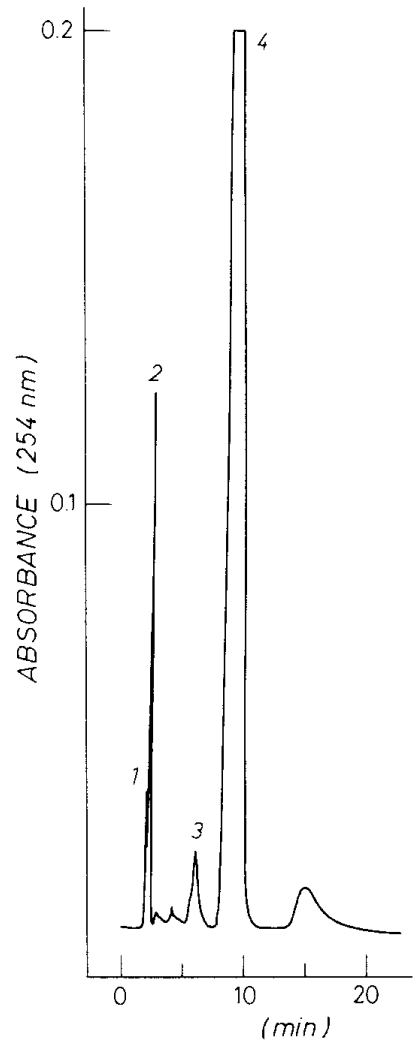

Fig. 2. Analytical chromatography of 2-methoxyethyl 1-methylethyl 2,6-dimethyl-4-(3-nitrophenyl)pyridine-3,5-dicarboxylate on a Nucleosil $\mathrm{C}_{18} 100 \AA$ A column $(10 \mu \mathrm{m}), 4.6 \times 250 \mathrm{~mm}$, in methanolwater (75:25) at a flow rate of $1 \mathrm{~mL} \mathrm{~min}{ }^{-1}$. Injection: $20 \mu \mathrm{g}$. Peak assignement: 1 = bis(2-methoxyethyl) 2,6-dimethyl-4-(3-nitrophenyl)-1,4-dihydropyridine-3,5-dicarboxylate; $2=2$-methoxyethyl 1-methylethyl 2,6-dimethyl-4-(3-nitrophenyl)pyridine-3,5-dicarboxylate; 3 = bis(1-methylethyl) 2,6-dimethyl-4-(3-nitrophenyl)-1,4-dihydropyridine-3,5-dicarboxylate; $4=2$-methoxyethyl 1 -methylethyl 2,6-dimethyl-4-(3-nitrophenyl)pyridine-3,5-dicarboxylate.

wider than that from an analytical sample. Under these conditions peaks will be asymmetric, showing sharp fronts and extended tails. A traditional way to optimize the load is to increase the injected quantity until the two peaks touch. This is called touching-band optimization.

Figure 3 illustrates the chromatograms that result from injecting different weights of solute onto an analytical column. As sample size is increased the bands will just touch. At large sample load, the components of the sample interfere and the elution peaks are modified. The touching bands approach is appropiate for research and development, where some grams of purified product will often suffice for a given application. The sample contains several impurities. However, only the impurity bands that are immediately adjacent to the product band are of interest in preparative chromatography.

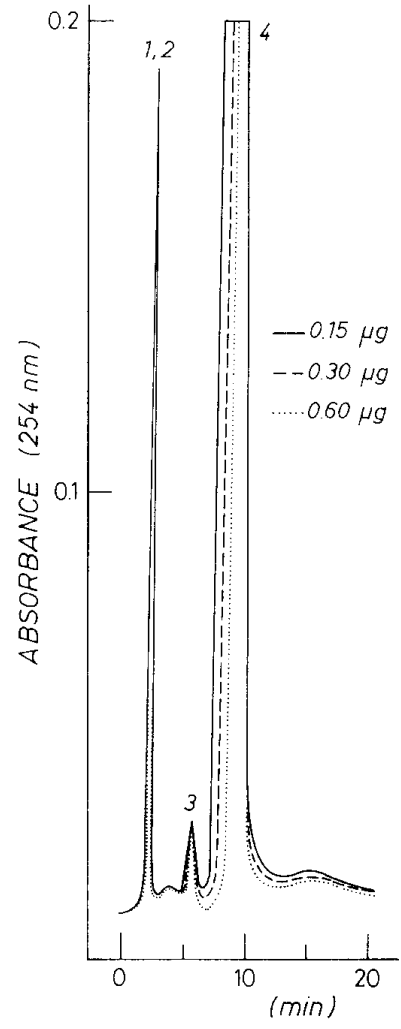

Fig. 3. Overload separation of 2-methoxyethyl 1-methylethyl 2,6dimethyl-4-(3-nitrophenyl) pyridine-3,5-dicarboxylate on a Nucleosil $\mathrm{C}_{18} 100 \AA$ column $(10 \mu \mathrm{m}), 4.6 \times 250 \mathrm{~mm}$, in methanolwater $(75: 25)$ at a flow rate of $1 \mathrm{~mL} \mathrm{~min}^{-1}$. Injections: $0.15,0.30$ and $0.60 \mu \mathrm{g}\left(5,10\right.$ and $20 \mu \mathrm{L}$ of a $30 \mathrm{mg} \mathrm{mL}^{-1}$ solution in methanol).

Having demonstrated the utility of a reversed-phase packing, we proceeded to scale up our preparative reversed-phase procedure, achieving higher sample loadings while maintaining good resolution. By keeping the concentration of feed solution at a constant value $\left(30 \mathrm{mg} \mathrm{mL}^{-1}\right.$ of crude pyridine dissolved in methanol) and varying the total injection sample $(5,10$ and $20 \mu \mathrm{L})$, we examined the loading effect [13-14]. Various sample amounts from $0.15 \mathrm{mg}$ to $0.60 \mathrm{mg}$ of crude pyridine were injected onto the analytical column. Separation of $0.60 \mathrm{mg}$ crude pyridine was carried out under the same conditions on the same Nucleosil $\mathrm{C}_{18} 100 \AA$ column $(4.6 \times 250 \mathrm{~mm})$. A decrease in peak resolution was observed.

The most obvious way to increase throughput is to increase the column bed volume by making the column wider or taller, or both. Enlarging the column diameter is the most practical means to achieve increased capacity. The optimized mobile phase of the analytical system was transferred without any modification to preparative HPLC. The column diameter was enlarged from $4.6 \mathrm{~mm}$ (analytical 


\section{Original articles}

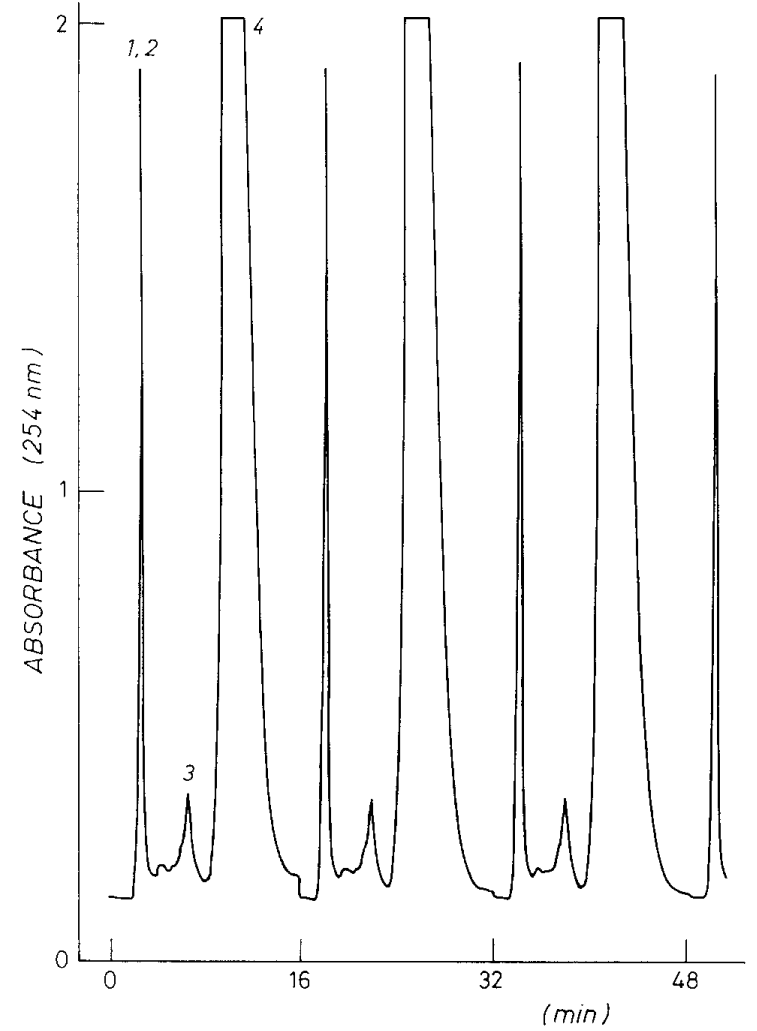

Fig. 4. Preparative chromatogram of 2-methoxyethyl 1-methylethyl 2,6-dimethyl-4-(3-nitrophenyl)pyridine-3,5-dicarboxylate on a Nucleosil $\mathrm{C}_{18} 100 \AA$ column $(10 \mu \mathrm{m}), 22 \times 250 \mathrm{~mm}$, in methanolwater (75:25) at a flow rate of $25 \mathrm{~mL} \mathrm{~min}{ }^{-1}$. Injection: $15 \mathrm{mg}$.

column) to $22 \mathrm{~mm}$ and the flow rate was increased from 1 to $25 \mathrm{~mL} \mathrm{~min}^{-1}$. The isocratic preparative separation was carried out with $15 \mathrm{mg}$ of crude pyridine (injected volume: $500 \mu \mathrm{L}$ of a $30 \mathrm{mg} \mathrm{mL}^{-1}$ solution in methanol). Concentration overload has been chosen because this is the most economical way of carrying out a preparative separation. Practically the same baseline resolution was achieved as in the analytical column. A minimal loss of resolution of the pyridine peaks from the other components of the sample at high loading demonstrates that the $100 \AA$ pore size of the packing material has a high available surface area. The preparative chromatogram is shown in figure 4. Many injections were made during several hours with a cycle period of $16 \mathrm{~min}$. The solvent was removed at $40{ }^{\circ} \mathrm{C}$ in a rotary evaporator.

A few grams (50 $\left.\mathrm{mg} \mathrm{h}^{-1}\right)$ of 2-methoxyethyl 1methylethyl 2,6-dimethyl-4-(3-nitrophenyl)pyridine-3,5dicarboxylate in high purity $(99.8 \%)$ were then isolated by preparative HPLC from crude material. The collected fractions were analyzed with analytical HPLC (Fig. 5). This purity is calculated using the area normalization method. It assumes that all components have been eluted and detected.

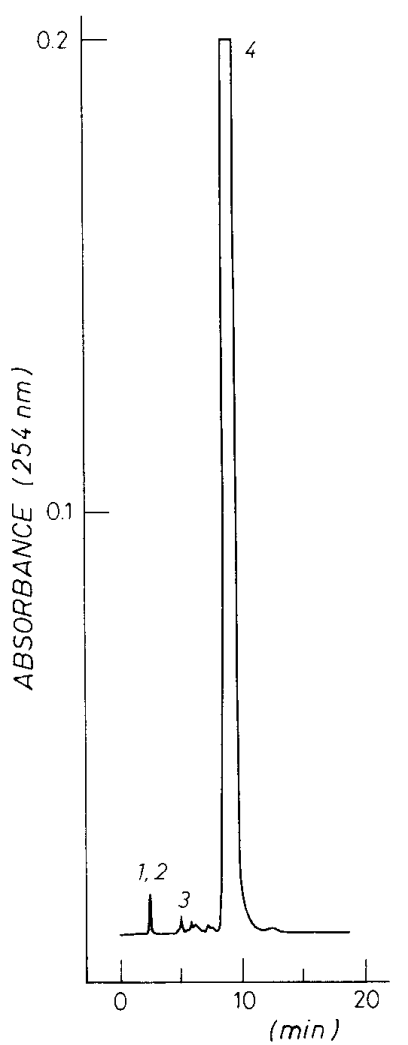

Fig. 5. Analytical HPLC of the purified 2-methoxyethyl 1methylethyl 2,6-dimethyl-4-(3-nitrophenyl)pyridine-3,5-dicarboxylate after preparative HPLC. The experimental conditions are shown in figure 2 .

The area of every peak is measured and this area is expresed as a percentage of the sum of the areas of all the peaks. In this work the objective has been to obtain some grams of analytically pure compound to use this purified material as standard.

2-methoxyethyl 1-methylethyl 2,6-dimethyl-4-(3-nitrophenyl)pyridine-3,5-dicarboxylate can be isolated and purified on both an analytical and a preparative scale from a crude feedstock using reversed phase columns. The purpose of this isolation was to obtain a standard for quantitative analysis. The high efficiency of preparative columns allows a peak resolution comparable to that obtainable under analytical conditions. Thus, the isolation of reaction products of high purity and in almost quantitative yield may be easily attained. The results obtained in these cases were satisfactory and indicated the general usefulness of the method

\section{Acknowledgements}

The author wishes to thank Astur Pharma (Asturias, Spain) for their gift of 2-methoxyethyl 1-methylethyl 2,6-dimethyl- 
4-(3-nitrophenyl)pyridine-3,5-dicarboxylate for this study, and Fernando Díaz for his helpful comments.

\section{References}

1. Muck, W. M. J. Chromatogr. 1995, A 712, 45-53.

2. Usune, S.; Katsuragi, T.; Furukawa, T. Can. J. Physiol. Pharm. 1995, 73, 1600-1604.

3. Muck, W. M., Tamaka, T., Ahr, G., Kuhlmann, J., Internat. J. Clin. Pharm. Therapeutics 1996, 34, 163-171.

4. Xi, D.; Kurtz, D. T.; Ramsdell, J. S. Biochem. Pharm. 1996, 51, 759-769.

5. Angelov, D. N.; Neis, W. F.; Streppel, M.; Andermahr, J.; Mader, K.; Stennert, E. J. Neuroscience 1996, 16, 1041-1048.

6. Bidlinmeyer, B. A. Preparative Liquid Chromatography, Elsevier, New York, 1987.
7. Guiochon, G.; Katti, A. Chromatographia 1987, 24, 165-189.

8. Subramanian, G. Preparative and Process-Scale Liquid Chromatography, Ellis Horwood, Chichester, 1991.

9. Nicoud, R. M.; Perrut, M. In: Chromatographic and Membrane Processes in Biotechnology, Costa, C. A.; Cabral, J., Eds., Kluwer Academic Publishers, Netherlands, 1991; pp 381-413.

10. Medina, I. J. Liq. Chrom. Rel. Technol. 1998, 21(17), 26892698.

11. Medina, I. J. Liq. Chrom. Rel. Technol. (accepted for publication).

12. Colin, H. In: Preparative and Production Scale Chromatography, Ganetsos, G.; Barker, P. E. Eds., Marcel Dekker, New York, 1993; pp 11-45.

13. Guiochon, G.; Sarker, M. J. Chromatogr. A 1995, 704, 247268.

14. Sarker, M.; Guiochon, G. J. Chromatogr. A 1995, 709, $227-$ 239. 